\title{
Growth rate of ascending thoracic aortic aneurysms in a non-referral-based population
}

\author{
Gabe Weininger ${ }^{1}$ (D, Makoto Mori ${ }^{1}$, Sameh Yousef ${ }^{1}$, David J. Hur ${ }^{2}$, Roland Assi ${ }^{1}$, Arnar Geirsson ${ }^{1}$ and \\ Prashanth Vallabhajosyula ${ }^{1^{*}}$
}

\begin{abstract}
Background: Prior studies on ascending thoracic aortic aneurysm (ATAA) growth rates have reported approximately $1 \mathrm{~mm}$ of growth per year but these studies are based on referral-based study populations which are biased towards the highest risk patients who may not represent the true natural history of aortic aneurysm disease. We aimed to characterize the growth rate of ATAAs in a non-referral-based population, using a large institutional database of computed tomography (CT) scans.

Methods: We queried the 21,325 CT scans performed at our institution between 2013 and 2016 on patients ages 50-85 years old for radiologic diagnosis of aortic aneurysm or dilatation. 560 patients were identified to have aortic dilatation $>4 \mathrm{~cm}$, of which 207 had follow-up scan intervals $>6$ months. This comprised our non-referral-based study population. Linearized annual aneurysm growth rates were calculated by dividing the change in aortic size by the time interval between $\mathrm{CT}$ scans.
\end{abstract}

Results: The median time interval between scans was 2.7 years (interquartile range [IQR] 1.5-4.2) for the 207 patients included in the study. The median initial aneurysm size was $4.3 \mathrm{~cm}$ (IQR 4.1-4.5). 38.2\% ( $n=79)$ of patients did not experience aortic dilatation. The median growth rate was $0.13 \mathrm{~mm} / \mathrm{year}$ (IQR -0.24 to 0.49 ). Of patients in the top quartile of growth rates, $26.9 \%$ of patients were female whereas $12.9 \%$ of patients were female in the bottom three quartiles of growth rates.

Conclusion: While some patients' ATAAs may grow at previously published rates of around $1 \mathrm{~mm} /$ year, this is not the predominant pattern in a non-referral-based population and may over-estimate the overall growth rate of ATAAs.

Keywords: Ascending aortic aneurysm, Growth rate, Referrel based population, Computed tomography

\section{Introduction}

The mostly asymptomatic nature of ascending thoracic aortic aneurysms (ATAAs) require characterization of the growth rate of ATAAs to inform the appropriate timing of surgical intervention and surveillance practices [1]. Prior studies on the ATAA growth rate have reported approximately $1 \mathrm{~mm}$ of growth per year but these studies are limited by small sample sizes, mixed imaging

*Correspondence: prashanth.vallabhajosyula@yale.edu

${ }^{1}$ Section of Cardiac Surgery, Yale University School of Medicine, 330 Cedar Street, Boardman Building 204L, New Haven, CT 06520, USA

Full list of author information is available at the end of the article modalities and measurement techniques, and are based on referral-based study populations [2]. Studies using referral-based study populations may be biased by the highest risk patients $[2,3]$ and the findings may not represent the true natural history of aortic aneurysm disease. We aimed to characterize the rate of ATAA growth in a non-referral-based population, using a large institutional database of computed tomography (CT) scans. original author(s) and the source, provide a link to the Creative Commons licence, and indicate if changes were made. The images or other third party material in this article are included in the article's Creative Commons licence, unless indicated otherwise in a credit line to the material. If material is not included in the article's Creative Commons licence and your intended use is not permitted by statutory regulation or exceeds the permitted use, you will need to obtain permission directly from the copyright holder. To view a copy of this licence, visit http://creativecommons.org/licenses/by/4.0/. The Creative Commons Public Domain Dedication waiver (http://creativeco mmons.org/publicdomain/zero/1.0/) applies to the data made available in this article, unless otherwise stated in a credit line to the data. 
dilatation. 560 patients were identified to have aortic dilatation $>4 \mathrm{~cm}$, of which 207 had follow-up scan intervals $>6$ months. This comprised our non-referralbased study population.

The double oblique technique was used to measure the maximum transverse diameter of the ascending aorta, from outer-to-outer edge (Visage 7, Visage Imaging, Inc., San Diego, CA). Final measurements were calculated as an average of 3 diameters measured 60-degrees apart from each other (Fig. 1). Linearized annual growth rate was calculated by dividing the change in aortic size by the time interval between $\mathrm{CT}$ scans.

Patient characteristics were compared between those with faster and slower growth rates using Wilcoxon ranked sum test for continuous variables and chisquared tests for categorical variables. Faster growth rates were defined as those in the top 25 percentile of growth rates in our study cohort. Continuous variables were summarized with median and interquartile range (IQR) with statistical significance defined as $p<0.05$.

The Institutional Review Board at Yale University approved this study and individual consent was waived (IRB 2000027551). The study followed the Strengthening the Reporting of Observational Studies in Epidemiology (STROBE) reporting guidelines for cohort studies.

\section{Results}

The median time interval between scans was 2.7 years (interquartile range [IQR] 1.5-4.2) for the 207 patients included in the study. The median growth rate was $0.13 \mathrm{~mm} /$ year (IQR -0.24 to 0.49 ). The median initial aneurysm size was $4.3 \mathrm{~cm}$ (IQR 4.1-4.5). 38.2\% $(n=79)$ of patients did not experience aortic dilatation. Of patients in the top quartile of growth rates (median $0.95 \mathrm{~mm}$ /year IQR $0.68-1.63$ ), $26.9 \%$ of patients were female whereas $12.9 \%$ of patients were female in the bottom three quartiles of growth rates (Table 1).

\section{Discussion}

Our results suggest that while some patients' ATAAs may grow at previously published rates of around $1 \mathrm{~mm} /$ year, this is not the predominant pattern and may over-estimate the overall growth rate of ATAAs. Referral-based study populations are often comprised of higher-risk patients who are more often symptomatic and experience aortic complications, including rupture and dissection, at higher rates $[1,4]$. This may contribute to an overestimation of the overall ATAA growth rate in the existing body of literature, which has placed the rate around

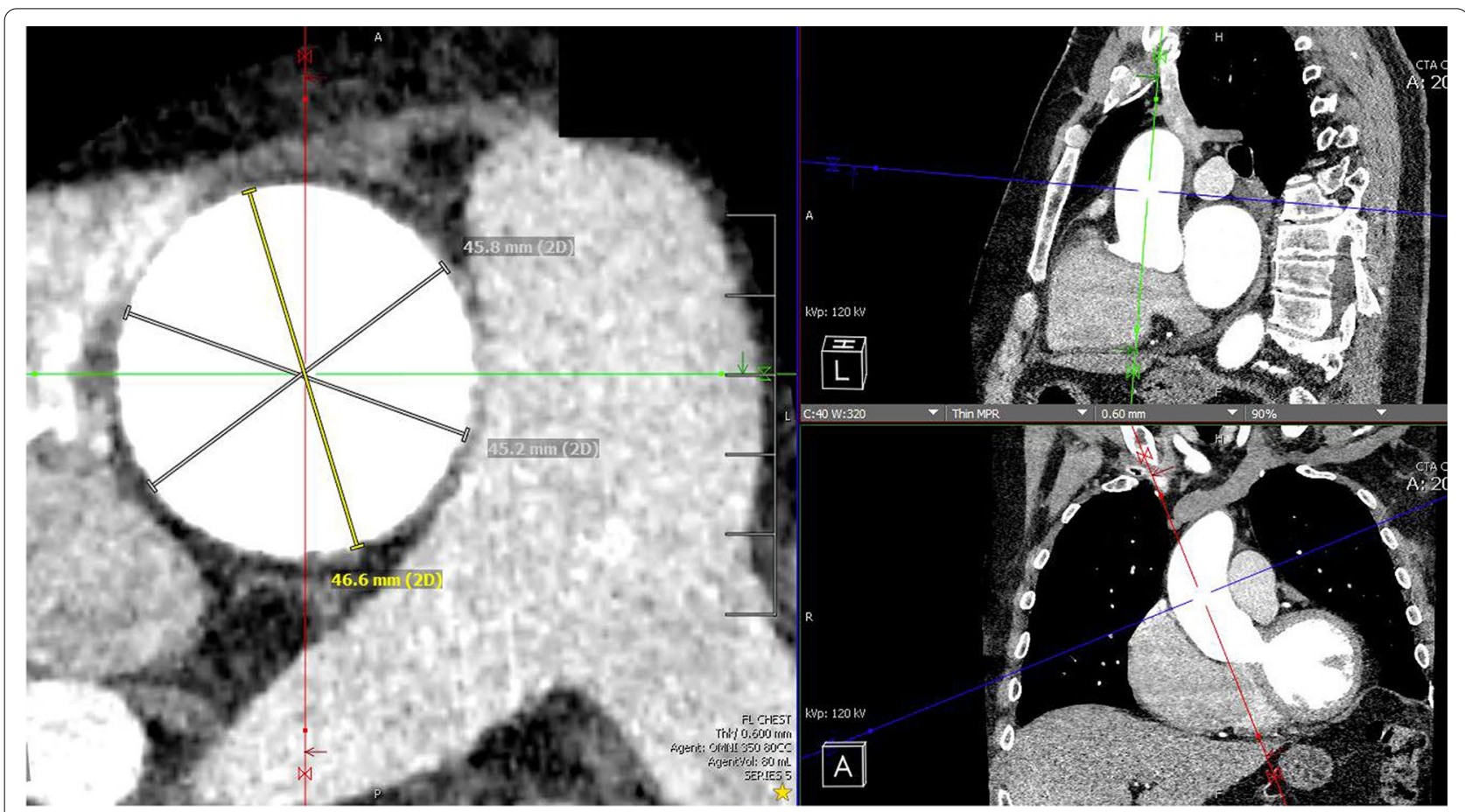

Fig. 1 Double oblique measurement of the ascending thoracic aorta. The figure shows the measurement of the ascending aorta using the double oblique technique. Maximum transverse diameter was measured on multiplanar reconstruction images in planes perpendicular to the aortic wall, from outer-to-outer edge. Final measurements were calculated as an average of 3 diameters measured at 60-degrees apart from each other 
Table 1 Patient characteristics

\begin{tabular}{|c|c|c|c|c|}
\hline Patient characteristics & Combined $(n=207)$ & Growers $(n=52)$ & Non-growers $(n=155)$ & $p$ Value \\
\hline $\begin{array}{l}\text { Initial aneurysm size }(\mathrm{cm}) \\
\text { Median [IQR] }\end{array}$ & $4.3[4.1-4.5]$ & $4.3[4.1-4.5]$ & $4.3[4.2-4.5]$ & 0.99 \\
\hline Growth rate (mm/yr) & $0.133[-0.24-0.49]$ & $0.95[0.68-1.63]$ & $-0.03[-0.4-0.2]$ & $<0.001$ \\
\hline Age & $74[67,80]$ & $74[67,81]$ & $74[67-80]$ & 0.66 \\
\hline BMI & $27.1[24.3-31.2]$ & $27.2[23.6-31.4]$ & $27[24.3-31.4]$ & 0.82 \\
\hline Sex (\% female) & $34(16.4 \%)$ & $14(26.9 \%)$ & $20(12.9 \%)$ & 0.03 \\
\hline Hypertension & $151(72.9 \%)$ & $41(78.9 \%)$ & $110(71 \%)$ & 0.35 \\
\hline COPD & $38(18.3 \%)$ & $9(17.3 \%)$ & $29(18.7 \%)$ & 0.98 \\
\hline Previous MI & $17(8.2 \%)$ & $6(11.5 \%)$ & $11(7.1 \%)$ & 0.47 \\
\hline Family history & $37(17.8 \%)$ & $8(15.4 \%)$ & $29(18.7 \%)$ & 0.73 \\
\hline Smoker & $10(48.3 \%)$ & $24(46.2 \%)$ & $76(49 \%)$ & 0.84 \\
\hline Aortic valve disease & $21(10.1 \%)$ & $6(11.5 \%)$ & 15 (9.7\%) & 0.91 \\
\hline Diabetes & $37(17.9 \%)$ & $11(21.2 \%)$ & $26(16.8 \%)$ & 0.61 \\
\hline $\mathrm{CHF}$ & $31(15 \%)$ & $11(21.2 \%)$ & $20(12.9 \%)$ & 0.22 \\
\hline
\end{tabular}

Bold indicates $p<.05$

$B M I$ body mass index, COPD chronic obstructive pulmonary disease, $C H F$ congestive heart failure, MI myocardial infarction

The table summarizes the patient characteristics of the 207 patients who were identified to have ascending aortic dilatation $>4 \mathrm{~cm}$ on computed tomography scans with follow-up intervals $>6$ months. Growers were defined as those in the top 25 percentile of growth rates in our study cohort. Characteristics were compared between the growers and non-growers using Wilcoxon ranked sum test for continuous variables and chi-squared tests for categorical variables

$1 \mathrm{~mm} /$ year $[2,3]$ in contrast to our finding of $0.13 \mathrm{~mm} /$ year with only a subset of patients growing at $\geq 1 \mathrm{~mm} /$ year. Other likely sources of overestimation include the use of axial aortic diameter measurements instead of the double oblique measurement technique [5] and combining ascending and descending thoracic aneurysms in the same study cohort [2].

Our study is limited by the use of contrast and noncontrast CT scans as well as ECG gated and nongated scans; though these factors are not consistently accounted for in other studies on ATAA growth rates, they could influence aortic diameter measurements.

\section{Abbreviations}

ATAA: Ascending thoracic aortic aneurysm; CT: Computed tomography; IQR: Interquartile range; ECG: Electrocardiogram.

\section{Funding}

This study was not funded.

\section{Declarations}

Competing interests

The authors declare no competing interests.

\section{Author details}

1 Section of Cardiac Surgery, Yale University School of Medicine, 330 Cedar Street, Boardman Building 204L, New Haven, CT 06520, USA. ${ }^{2}$ Section of Cardiovascular Medicine, Yale School of Medicine, New Haven, CT, USA.

Received: 26 May 2021 Accepted: 22 January 2022

Published online: 02 February 2022
References

1. Elefteriades JA. Indications for aortic replacement. J Thorac Cardiovasc Surg. 2010;140(6, Supplement):S5-9.

2. Oladokun D, Patterson BO, Sobocinski J, et al. Systematic review of the growth rates and influencing factors in thoracic aortic aneurysms. Eur J Vasc Endovasc Surg. 2016;51(5):674-81.

3. Hiratzka LF, Bakris GL, Beckman JA, et al. ACCF/AHA/AATS/ACR/ASA/ SCA/SCAI/SIR/STS/SVM Guidelines for the diagnosis and management of patients with thoracic aortic disease. J Am Coll Cardiol. 2010;55(14):e27-129

4. Coady MA, Rizzo JA, Hammond GL, et al. What is the appropriate size criterion for resection of thoracic aortic aneurysms? J Thorac Cardiovasc Surg. 1997;113(3):476-91.

5. Mendoza DD, Kochar M, Devereux RB, et al. Impact of image analysis methodology on diagnostic and surgical classification of patients with thoracic aortic aneurysms. Ann Thorac Surg. 2011;92(3):904-12.

\section{Publisher's Note}

Springer Nature remains neutral with regard to jurisdictional claims in published maps and institutional affiliations.

Ready to submit your research? Choose BMC and benefit from:

- fast, convenient online submission

- thorough peer review by experienced researchers in your field

- rapid publication on acceptance

- support for research data, including large and complex data types

- gold Open Access which fosters wider collaboration and increased citations

- maximum visibility for your research: over 100M website views per year

At BMC, research is always in progress.

Learn more biomedcentral.com/submissions 